\title{
Assessing the impact of the Three Gorges Reservoir on eco-hydrological regimes in the middle and lower Yangtze River, China
}

\author{
wenxian guo ${ }^{1}$, Haotong Zhou $^{1}$, Xuyang Jiao ${ }^{1}$, Lintong Huang ${ }^{1}$, and Hongxiang Wang ${ }^{1}$ \\ ${ }^{1}$ North China University of Water Resources and Electric Power
}

February 28, 2022

\begin{abstract}
The flow regime is regarded as the key driver of the structure and function of riverine ecosystems. To reveal the changes in the ecohydrological pattern of the middle and lower reaches of the Yangtze River after the impoundment of the Three Gorges Reservoir. Hydrological data from Yichang, Hankou, and Datong stations from 1960 to 2020 were selected to detect the annual mean flow changes trend by three techniques. The degree of hydrological alteration was also evaluated using the Indicators of Hydrologic Alteration (IHA)/Range of Variability Approach (RVA). The results show that: (1) The average annual flow of the Yangtze River from 1960 to 2020 shows a decreasing trend. (2) The abrupt change of annual average flow occurred in the year 2003, which reflects the significant effect of the Three Gorges reservoir on the flow regime. The alteration degrees of the Yichang, Hankou, and Datong gauge stations are 65\%, 58\%, and 46\%, respectively. (3) The Three Gorges Reservoir caused changes in the flow pattern of the Yangtze River and had a particular impact on the fish population structure. The study provides a scientific reference for the ecological protection of water resources in the middle and lower reaches.
\end{abstract}

\section{Hosted file}

manuscript_Assessing the impact of the Three Gorges Reservoir on eco-hydrological regimes in the middle available at https://authorea.com/users/462686/articles/558050-assessing-the-impact-of-thethree-gorges-reservoir-on-eco-hydrological-regimes-in-the-middle-and-lower-yangtzeriver-china 